\title{
National Images - Challenges for South Asian Sub-regional Nations to Sustain Tourism Growth
}

\author{
Rabi Jung Pandey*
}

\begin{abstract}
An image on tourism industry products gives potential traveller an important sense of emotional security. They can establish harmonious relationship between themselves and the outside world. National image is a long term investment and should be considered every time a decision is made at high or low levels of management. Marketers of the tourism product should not underestimate the value of a national image and its effect upon tourist behaviour. The steady growth in the world tourism market has earmarked its importance globally. Inevitably such tourism activities have an impact on wider economies, in both the developed and the developing world. Realizing the fact and importance of tourism, there is growing awareness worldwide. However, there is still relatively little appreciation of the specific operating characteristics of tourism firms, and especially of tourism entrepreneurship within developing countries. The development of national tourism policies, long-term tourism master plans, and tourism marketing strategies clearly highlights the significance that governments all over the world are attached and giving utmost priority to the industry. It is equally important to understand that the reliance on international tourism as a strategy for economic development might be precarious for the country. This is justified by the fact that it is so often associated with a dependency upon external sources of growth. This type of situation will be observed by those countries, which will be having their internal political conflicts, or in other socio-political tribulations. Therefore, such external sources at that time tend to be fickle in nature. Tourism being very sensitive and psycho graphic industry, choices of tourist destinations is susceptible to large fluctuations, particularly because of economic conditions in the tourist's country of origin or the political situation in the holiday destination. Likewise, there also exist significant socio-economic and geographical dimensions of tourism dependency. The growth of the
\end{abstract}

\footnotetext{
${ }^{*}$ Mr. Pandey is the Director of Nepalese Tourism Research and Service Center (NTRSC).
} 
tourist industry and its potential for stimulating economic development through service sectors has contrived an important point in much of the literature on tourism. South Asian Sub-regional countries are considering tourism as an important industry for their livelihood. Different concepts and different philosophies on tourism are gaining wider recognition in this sub-region. That is why, research and studies going on widely into these areas. However, regardless of considerable dispute on the subject there is still little conformity as to tourism's role in economic development where the governments will be having many more other socio-economic obligations. In such countries, the overall picture of tourism's role is found to be somewhat blurred with some challenges, not only by the different assessments of economic development, but also by its socio-cultural and environmental implications as well.

Keywords: national image, challenges, SASEC, destination choice, sustainability

\section{Introduction}

The study of national image is somewhat recent addition in to the field of tourism research. However, various study show that national images do, indeed, influence tourist behaviour ( Echtner and Ritchie,1991; Chon,1992a; Pearce,1982; Hunt,1975). Every individual is believed to have own perception of reality. Of all the stimuli that confront traveller, he/she receives only those that conform to his/her own image. Traveller sees and hears not what is there, but what they prefer to see or hear (Mayo,1973)

National image has thought to have a decisive role in an individual's travel purchase related decision making process. The individual travellers satisfaction / dissatisfaction with a travel purchase largely depends on a comparison of his/her expectation about the destination, or a previously held destination image, and their perceived performance of the destination (Chon 1990,1992).

However, the remarkable growth in the tourism industry during the last eighty years has brought major challenges in tourism marketing. With the development of new area in the world for tourism, the destination choices available to consumers have continued to expand. Moreover, present consumers who are facilitated by increased leisure time, wider and varied sources of information, high disposable income and efficient transport networks, have ample opportunity to choose the best one from larger variety of nations. As a result, in this complex and competitive global market place, the national marketers are facing them busy, influencing consumer to make decision in their favour. This challenging situation has created the need for positioning the nation into an effective way (Calantone et al., 1989). Furthermore, various study suggest that, in order to promote a nation as a destination successfully in the targeted 
market, the product should be favourably differentiated from the competitors or it should be positioned positively in the minds of the consumers (Echtner and Ritchie, 1991; Cohn, 1989, 1990, 1992; Christopher, 1984; Batson, 1991), whereas, creation and management of a distinctive and appealing perception or image, is the key element of the positioning process.

As suggested by Goodrich (1978) and Chon (1990) the strong, positive images are more likely to be marketed and preferred in the travel decision process. The awareness of the tourism product which is made up of experiences, learning, emotions, and perceptions, can be described as knowledge producing a specific image of the tourism product, which could affect an individual's preferences and motivates towards tourism. However, while developing a strong national image, it needs creativity and hard work. It cannot be implanted in the public's mind overnight nor seeded by one media vehicle alone. Furthermore, it should be carried out in every communication vehicle available, with regular intervals. Images, beliefs and perceptions of an individual what Hunt (1975) suggests will contribute for the successful development of new tourist areas, equally, as a tangible recreation facilities and other tourist resources contributes towards destination.

Pizam et al., (1978) supporting Hunt suggest that the consequence of the interaction between a tourist experience at the destination areas and the assumptions he/she had about the destination is the satisfaction of the tourist. Mayo (1980) also state that among alternative choices available to travel destination, the subjective judgement a traveller makes about alternatives available is dependent on a number of factors among which the most important of these of the image of the each alternative and its perceived ability to satisfy his/her needs. To conclude, traveller's satisfaction and dissatisfaction is the comparison between travellers' accumulated image and actual image which is gathered from travel experience. The change arising from satisfaction and dissatisfaction would have a lot to do with the national image.

\section{Condition to Travel}

It is argued that economic and cultural distance and the relative cost of living at the destination will attribute the aptness of a traveller to particular destinations. Economic distance are associated with the time and cost of reaching a destination, whereas cultural distance relates the differences in cultural between the origin area and destination. Cost at a destination are not an absolute quantity, but have to be considered reciprocal to the value of the travellers own current (Cooper et al., 1993).

According to Pearce (1985), to be able to satisfy their desire to travel, travellers must be able to meet various conditions, such as be able to afford both time and money and should be able to overcome obstacles to travel. The economic distance and the cost at a destination defined by Cooper et al. seem to have the same notion which Pearce has described as time and money. 
The growth of leisure time which has brought about by technological and other improvements has greatly increased the amount of time available for tourism, especially in developed nations. The technological development with the application of sophisticated marketing and management techniques has helped to stimulate to the tourism activities. According to Cooper et al. (1993) the ability to undertake the trip and the nature of that trip will be influenced by two broad interrelated factors: (a) life style - Which include income employment, holiday entitlement, educational attainment and mobility; and (b) life cycle - Where the age and domestic circumstances of an individual affect both the amount and type of tourism demanded.

Among the life style factors, income and employment are closely linked and employ importance upon both the level and the nature of tourism demanded by an individual, while time budget, leisure time and paid holiday entitlement is complex. Paid holiday entitlement tends to be more generous in developed economies and less so in the developing world. Whereas, level of educational attainment is an important determinant of travel aptness as education extends perspectives and stimulates longings to travel.

In life cycle factors, the penchant to travel, and the type of tourism experience demanded, is closely related to an individual's age. At each stage in the life-cycle individuals can be thought of as having preoccupation's, interests, and activities. Each stage in the life-cycle is said to characterise by particular combinations of the three factors.

Therefore, the demand for tourism is influenced not only by the amount of leisure time available but also the distribution of that time throughout the year. In most countries the demand for tourism is marketed seasonally. Factors such as institutionalised holiday periods when schools and many businesses close down or certain groups traditionally take their holidays and climatic conditions in the market areas and destinations give rise to 'peak' and 'off' seasons. To be able to travel, tourists must not only have the time but also sufficient financial resources to enable them to do so. Hence, it can be concluded that the determinants of tourist demand are basically, income, time, and age.

Lavery, et al (1990) asserts that as tourism became more and more organised activity, the organisation of travel have become more established institutions. The onset of the airline industry signalled the beginning of the end, not only for long distance rail services but more decisively, for the great steamship companies. In the 1950 's and 1960's, international tourism began to reach mass markets in many countries. This was stimulated by the development of relatively cheap and fast air transport and by the application of sophisticated marketing and management techniques by producers in what was now recognised to be the tourism industry. The domain for international tourism has increased steadily since 1960 and the total number of arrivals has grown dramatically. 


\section{Destination Choice Behaviour}

In recent years, because of the rapid growth of both travel demand and the tourist industry, the need to study the nation as destination - choice process has become more important. Together with this growth, the struggle of the industry to attract more potential tourists has also grown. At the same time, tourist have become more experienced and sophisticated in both destination choice and their expectations towards "tourism product". There is no doubt, therefore, that solving the destination - choice perplexity and constituting a sound theoretical framework for this process are no longer becoming a matters of purely academic interest, but also has become applicable to the highly sensitive tourist industry, urging a better understanding of this process. This situation has created a fundamental question as to the course of action that should be taken in order to attain a better understanding of the mechanism behind the destination - choice process.

Mansfeld (1992) and Chon (1990) asserts that some factors will effect on tourist movement just before starting of their actual trip. The researchers have named it as determinants for destination choice. In this approach it has been assumed that a variety of tourist needs, expectations, and backgrounds will result, different choice process, producing various patterns of tourists.

It has been argued that, earlier mathematics and economics were the only theoretical contributing factor to understand the decision making process. Which in later has found to introduce as a normative decision theory as probability, utility, and heuristics. It is argued that, this decision theory has been captivated from the social sciences, especially psychology and social psychology. Moreover, these closely related disciplines have dominated research into decision problems at both individual and society (Edwards et al., 1965; Lee, 1971; Savage, 1954; all cited in Mansfeld, 1992).

At present, in most of social sciences, it is argued that research into the decision making aspects is dominated by the random - utility theory and the probabilistic approach. Its advantage over the rational deterministic approach is found to believe in assumption which lies in the utility or utilities of a certain alternatives those are composed of both rational and irrational elements. By analysing them both, Mansfield (1992) argues that one can reveal a more sensible understanding of their nature and the pertinent consequence of their influence on the decision process and its repercussions. Many, social scientists believe that as with many other kinds of choices, the nation as destination choice of tourists involves a degree of uncertainty (Mathieson and Wall, 1982).

With reference to basic tourist conditions such as climate, quality of the services, quality of the accommodations, and the attitude of the hosts sometimes are unknown at the time when decisions are being made. Prevailing sources of tourist information can only exhibit a picture of the probability, of acquiring a given product or services 
at a particular potential destination, on the basis of the image it has created. This suggests that the random utility based behavioural probabilistic approach should be adopted for the study of the tourist choice against the disadvantage of the normative - rational approach. According to the later approach, the literature suggests that individual goes through several decision stages as shown in Figure 1.

\section{Figure 1 - Model of Tourist Destination Choice}

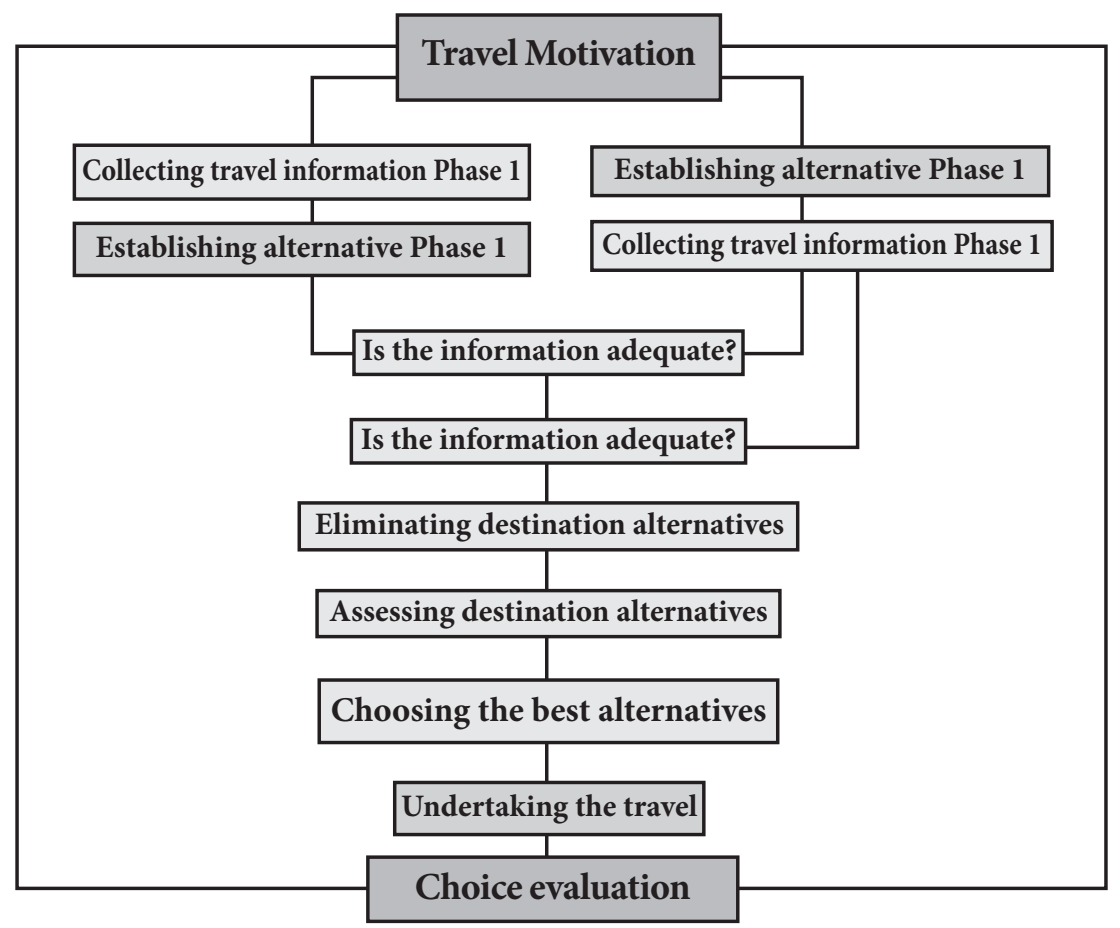

Source : Mansfeld (1992)

These destination choice processes is very much controlled by both the push and pull factors that design travel behaviour. Factors which motivate an individual traveller are "push" factors, and this motivation process, or push, is aggravated by the "pull", which attractive tourist destination areas exert upon travellers. Further, the "push" and "pull" factors, help account for travel patterns in the world today on the local, national and international scale. Whereas, two factors operating together function as antecedent events for an individual's travel motivation (Chon, 1990). However, it is argued that a primary image of the destination is constructed at the point when the push and pull factors co-exist. Furthermore, individual traveller's initial decision to travel to the destination is the sum of the two components: the individual traveller's 
perception of the attractiveness of outcomes related to his travel objectives; and the perceived beliefs and likelihood of accomplishing his or her needs and wants.

However, the smallest group affecting an individual's decision is the family. Some researchers (Van Raaij and Francken, 1984) suggest that destination choice is an entire family rather than an individual decision, whereas, other study (Jenkins and Henry, 1982), show that husband will have the major role in forming the destination - choice process, leading wife and the children's contribution unpretentious.

\section{South Asian Region as Tourism Destination}

According to the UNWTO, international tourism and travel now constitutes the world's largest and most rapidly expanding industry with growth over 5 per cent annually. Globally, more than 1087 million international tourists move from their place of permanent residence each year, and this figure is expected to reach 1.6 billion by 2020 (UNWTO, 2014). Given the diverse nature of tourism activity, it follows that there exist an equally diverse range of both positive and negative impacts. At the local and national level, the economic benefits of tourism are frequently cited by every nation to be the most significant factor. However, in addition, social and environmental opportunities are also considered, which include an improved community infrastructure and conservation of the environment. To judge the benefits exactly, the negative impacts that accrue by tourism should be evaluated. It is increasingly recognised that tourism should use and adopt natural and protected areas to facilitate wider social, economic and environmental development - and that it should be sustainable.

As has been defined by UNWTO (2005), 'sustainable tourism development meets the needs of the present tourists and host countries while protecting and enhancing opportunity for the future development'. Likewise, it is envisaged as leading to management of all resources in such a way that economic, social and aesthetic needs are fulfilled while on maintaining cultural integrity, essential ecological processes, biological diversity and life support system.

Pondering over the above definition, it is cleared that sustainable tourism development pose challenges to the host countries regarding improving the living standard both in the short and long term; satisfying the demands of the growing numbers of tourists and continue to attract them. But at the same time the natural environment must also be safeguarded. Above all, new knowledge and skill need to be developed among local people to attain sustainability by involving them in the management of their tourism resources. This ultimately will benefit the local people directly from the utilisation of these resources creating positive image of the host countries/destinations. With the new knowledge and skills, it will help local people to develop tourism in a sustained way with threefold interactive development system, where, economy will be linked with environment and society. Proper management 
of natural resources and the environment will keep all these three elements of development moving forward without harming others.

The South Asian region and in particular the sub region comprising Nepal, Bangladesh, Bhutan, Sri Lanka and Indian with South Asia Sub regional Economic Cooperation (SASEC) is endowed with diverse cultural and natural resources. It includes many natural and cultural heritage sites inscribed in the World Heritage list, an ancient cultural heritage dating back over 5,000 years, and a rich diversity of ethnic groups with distinctive lifestyles. The sub region is the ancient heartland of Buddhism, and contains a landscape that includes the world's highest mountain Sagarmatha (Mt. Everest) in the Himalayan range, and also some of the world's largest coastal mangrove forests and longest sea beaches, as well as containing internationally recognized biodiversity hotspots (ADB 2008).

The unique natural and cultural heritage endowments of the sub region itself has attracted an estimated 9.2 million international tourist arrivals in 2013 with average length of stay of estimated at 15.2 days and average spending of $\$ 215.32$ per day (excluding Bangladesh) (Table 1). About $42 \%$ of arrivals in these countries originate from Europe dominated by the UK and France. About 22\% market share comes from within the sub region (SAARC countries), 11\% from East Asia dominated by Japan, South Korea and the People's Republic of China, followed by various smaller markets that together account for $25 \%$ of the market. Pilgrimage, visiting friends and relatives, and other leisure-orientated travel comprise the main reason for visiting the sub region (GON 2013, GOI 2013, SLTDA 2013, TCB 2014, UNWTO 2014a).

In 2010, the SAARC countries had attracted around 7.3 million international tourists (Table 1) who stayed for an average of 14.9 days and spent an average of $\$ 121.20$ per day. However, in 2013, the annual average growth in tourism to these countries sustained $10.53 \%$ or nearly 2.1 times the growth of global international tourism. Likewise, Bhutan and Sri Lanka have experienced a massive growth of $10.25 \%$ and $26.7 \%$ respectively in 2013 over the period 2012. Similarly, in 2013, Bhutan has recorded the highest average spending per international tourist per day with $\$ 572$ followed by Sri Lanka and India with \$ 156.5 and \$ 90 per tourist per day respectively. Comparatively, Nepal lags far behind among other SASEC member nations to motivate tourist to spend except Bangladesh, which does not exhibit any tourist statistics after 2010 . 
Table 1: International Tourist Arrivals to SASEC Countries (2008 - 2012)

(In Thousands)

\begin{tabular}{|c|c|c|c|c|c|c|c|c|c|}
\hline \multirow{2}{*}{ SASEC Countries } & \multicolumn{6}{|c|}{ International tourists Arrivals } & \multirow{2}{*}{$\begin{array}{c}\text { Arrivals \% } \\
\text { Change } \\
2012 / 13\end{array}$} & \multirow{2}{*}{$\begin{array}{c}\text { Average } \\
\text { length of stay } \\
(2013)\end{array}$} & \multirow{2}{*}{$\begin{array}{c}\text { Average } \\
\text { spending per } \\
\text { day US\$ (2013) }\end{array}$} \\
\hline & 2008 & 2009 & 2010 & 2011 & 2012 & 2013 & & & \\
\hline Bangladesh & 349 & 267 & 303 & N/A & N/A & N/A & N/A & $\mathrm{N} / \mathrm{A}$ & N/A \\
\hline Bhutan & 28 & 23 & 41 & 64 & 105 & 116 & 10.25 & 6.85 & $572 \#$ \\
\hline India & 5283 & 5168 & 5776 & 6303 & 6577 & 6968 & 5.9 & $31.2^{* *}$ & $90^{* *}$ \\
\hline Nepal & 500 & 510 & 603 & 736 & 803 & 798 & -0.7 & 12.6 & 42.8 \\
\hline Sri Lanka & 438 & 448 & 654 & 856 & 1006 & 1275 & 26.7 & $10^{* *}$ & 156.5 \\
\hline $\begin{array}{l}\text { Total SASEC } \\
\text { Countries (Millions) }\end{array}$ & 6.598 & 6.416 & 7.363 & $7.959^{*}$ & $8.491^{*}$ & $9.156^{*}$ & $10.53^{*}$ & $15.2^{*}$ & $215.32^{*}$ \\
\hline $\begin{array}{l}\text { Total South } \\
\text { Asia (Millions) }\end{array}$ & 10.3 & 10.1 & 12 & 13.7 & 14.4 & 15.5 & 6.1 & & \\
\hline
\end{tabular}

${ }^{*}$ Excluding figures from Bangladesh

** Figure indicates of 2012

\# Average spending by International visitors only

Source: UNWTO, 2008 - 2013, and other specific country Annual Statistical Reports $(2008$ - 2013)

\section{Challenges to SASEC Countries to meet tourism demand \\ Nepal}

Tourism Cluster Analysis for Nepal Competitive Industry Diagnostic report prepared by World Bank in 2013 indicates that Nepal has yet to show up on the list of top destinations for high-end Chinese, Indian, Western European and US markets. Although wealthy travelers from those markets do visit Nepal, the country itself ranks below other destinations popular with wealthy travelers - particularly those from Asia. For instance, the top ten holiday destinations for China outbound travel in 2012 were Hong Kong $(6,281,317)$, Macau $(3,275,065)$, TaiwanÊ(2,761,160), Thailand $(2,698,199)$, South KoreaÊ(2,249,438), Singapore $(1,358,139)$, JapanÊE(1,162,770),

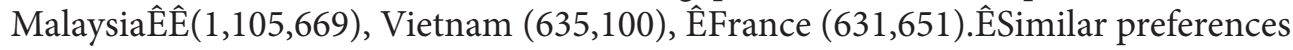
can be observed with wealthy Indian and other Asian markets.

Similarly, this study also reveals that Nepal has a considerable mix in arrivals, although Asia accounts for just over half (57\%) of all international visitors in 2012. India traditionally contributes the largest share of international arrivals (due to its geographic proximity and strong cultural ties) followed by China (8.9\%) and Sri Lanka (8.7\%) respectively. The Indian market share, however, has declined from its 1999 peak of one third of total arrivals (33.4\%) to $23.2 \%$ in 2013 . With almost 180,974 arrivals in 2013 (all by air as land arrivals are not recorded), India remains a major generating market for Nepal (MoCTCA, 2013). Other main source markets for Nepal in 2013 in order of size are USA (47,355), Thailand (40,969), UK $(35,668)$, and Republic 
of Korea (19,714). Most Sri Lankans (97\%) and Thais (82\%) are arriving by land to visit Lumbini with short stay and generally low spend patterns.

According to MoCTCA (2013), total international arrivals in Nepal for 2013 have been registered as 797,616 persons with decrease of $0.7 \%$ over 2012 and $57 \%$ increase from 2009 (509,956). However, arrivals in 2011 had registered $22.1 \%$ growth $(736,215$ visitors) over the year 2010, which can be considered a positive response to Nepal Tourism Year (NTY 2011) in terms of visitor growth (Table 1). Looking at the international market and growth trends, Nepal's neighbors are amongst the fastest growing spenders: China (38\%) and India (32\%). Other top spending markets with substantial Buddhist populations include South Korea, Japan and Thailand (UNWTO 2014). Asia and the Pacific recorded the fastest growth across all UNWTO regions, with a $7 \%$ increase in international arrivals comprising average annual growth of $6 \%$, 9.4\%, 4.1\% and 4.4\% of North-East Asia, South-East Asia, Oceania and South Asia respectively. About $75 \%$ of all visitors to Nepal enters by air to Kathmandu, currently the only international airport in the country. The average length of stay in 2013 was 12.6 days, which was 3.5\% more compared to the previous year (MoCTCA 2013). To apprehend a greater share of wealthy travelers, Nepal still need to focus on improving the quality of its current supply of tourism services including quality accommodation facilities, and complement these with high standard tours, attractions and activities that match high-end western, eastern, and north \& south neighboring market demand.

According to MoCTCA (2013), over 12 year's period, the country has experienced a spectacular change on accommodation sector. The total number of registered tourist standard hotels in Kathmandu Valley and outside Kathmandu has decreased from 439 and 449 in 2001, to 335 and 272 hotels in 2006 respectively, reflecting the period political conflict in the country (Table 2). With the revival of tourism following the peace agreement in 2006, the total number of hotels has recovered to 422 and 314 in 2009. However this was still 4\% lower in Kathmandu Valley and 30\% lower outside Kathmandu than in 2001. 
Table 2: Hotels available in Kathmandu Valley and outside Kathmandu 2001 to 2013

\begin{tabular}{|c|c|c|c|c|c|c|c|c|c|c|c|c|c|c|c|}
\hline \multirow{4}{*}{$\begin{array}{c}\text { Hotel } \\
\text { Category }\end{array}$} & \multicolumn{15}{|c|}{ Year } \\
\hline & \multicolumn{3}{|c|}{2001} & \multicolumn{3}{|c|}{2006} & \multicolumn{3}{|c|}{2009} & \multicolumn{3}{|c|}{2012} & \multicolumn{3}{|c|}{2013} \\
\hline & \multicolumn{2}{|c|}{$\begin{array}{c}\text { Number } \\
\text { of Hotels }\end{array}$} & \multirow[t]{2}{*}{$\begin{array}{c}\text { Number } \\
\text { of Rooms }\end{array}$} & \multicolumn{2}{|c|}{$\begin{array}{c}\text { Number } \\
\text { of Hotels }\end{array}$} & \multirow[t]{2}{*}{$\begin{array}{c}\text { Number } \\
\text { of Rooms }\end{array}$} & \multicolumn{2}{|c|}{$\begin{array}{c}\text { Number } \\
\text { of Hotels }\end{array}$} & \multirow[t]{2}{*}{$\begin{array}{c}\text { Number } \\
\text { of Rooms }\end{array}$} & \multicolumn{2}{|c|}{$\begin{array}{c}\text { Number } \\
\text { of Hotels }\end{array}$} & \multirow[t]{2}{*}{$\begin{array}{c}\text { Number } \\
\text { of Rooms }\end{array}$} & \multicolumn{2}{|c|}{$\begin{array}{c}\text { Number } \\
\text { of Hotels }\end{array}$} & \multirow[t]{2}{*}{$\begin{array}{c}\text { Number } \\
\text { of Rooms }\end{array}$} \\
\hline & 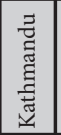 & $\begin{array}{l}\frac{0}{0} \\
\frac{0}{0} \\
0\end{array}$ & & 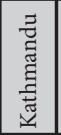 & $\begin{array}{l}\frac{7}{0} \\
\frac{0}{2} \\
0 \\
0\end{array}$ & & 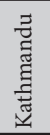 & $\begin{array}{l}\frac{0}{0} \\
0 \\
0 \\
0\end{array}$ & & 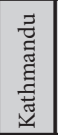 & $\begin{array}{l}\frac{0}{0} \\
0 \\
0 \\
0\end{array}$ & & 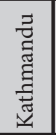 & 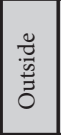 & \\
\hline 5 Star & 5 & 1 & 1051 & 8 & 1 & 1539 & 8 & 2 & 1539 & 8 & NA & 1539 & 8 & N/A & 1539 \\
\hline 4 Star & 8 & & 755 & 2 & & 190 & 2 & & 190 & 2 & NA & 190 & 2 & N/A & 190 \\
\hline 3 Star & 12 & 2 & 482 & 12 & 5 & 455 & 11 & 6 & 372 & 15 & NA & 596 & 15 & N/A & 596 \\
\hline 2 Star & 26 & 6 & 1085 & 30 & 6 & 1223 & 27 & 4 & 1138 & 29 & NA & 1213 & 26 & N/A & 1093 \\
\hline 1 Star & 25 & 12 & 653 & 29 & 12 & 725 & 26 & 11 & 564 & 26 & NA & 564 & 24 & N/A & 483 \\
\hline Non Star & 230 & 234 & 2812 & 254 & 248 & 3228 & 348 & 291 & 5010 & 442 & NA & 6985 & 482 & N/A & 7934 \\
\hline $\begin{array}{l}\text { Registered } \\
\text { \& Under } \\
\text { Construction }\end{array}$ & 133 & 194 & 5186 & & & - & & & - & & & - & & & \\
\hline Total & 439 & 449 & 12024 & 335 & 272 & 7360 & 422 & 314 & 8813 & 522 & NA & 11087 & 557 & N/A & 11835 \\
\hline
\end{tabular}

Source: MoCTCA Nepal Tourism Statistics, 2001- 2013

NB: No data available for Hotels outside Kathmandu from 2010

Despite political upheavals, investment in hotels in Kathmandu in recent years has picked up with an increase in numbers representing 464 in 2010, 503 in 2011, 522 in 2012 and 557 in 2013. However most of the growth is in the low end of the market. The Valley's eight five-star hotels with 1,539 rooms are unchanged since 2006. At this point in time, a total of 557 hotels with 11,835 rooms are available in the Kathmandu Valley to cater over 800,000 visitors, in contrast to 2001 when 230 hotels with 6,838 hotel rooms provided for 300,000 arrivals (by air only) (Table 2). However, as only three - four - and five-star hotels are considered, there were 2,325 rooms in 2013, an increase of only 37 rooms from 2001 (MoCTCA, 2014).

According to the World Bank study (2013), Kathmandu's registered standard (starred) accommodation facilities have achieved an average $67 \%$ room occupancy in 2012, which is higher than the national average occupancy of $62 \%$, with three night average length of stay. It could have been the reason that with increased bookings for hotel rooms, some of the Kathmandu five-star hotels planned refurbishments, and new extension. Likewise, it has also been argued that Êprojects have been attracting massive investments from both domestic and foreign investors. However, it reveals that still this does not include big projects, mainly four-star and five-star hotels.

At this instant, it has been quite urgent that Nepal's tourism industry needs lots of upgrading and enlargement eyeballing at the global market trend, and needs to learn the best practices from the outstanding progress made by the Asia Pacific 
countries together with the neighbouring India and Sri Lanka (Table 3) which have substaintial capacity to hold high-end markets with standard accommodation facilities. It is anticipated that a number of international franchises and chains will be back and some new brands will be expecting their way into Nepal to meet global demand for wealthy and brand loyal travellers for quality tourism.

Table 3: Accommodation facilities available in SASEC Countries 2013

\begin{tabular}{|c|c|c|c|c|c|c|}
\hline \multirow{2}{*}{\multicolumn{2}{|c|}{ Hotel Category }} & \multicolumn{5}{|c|}{2013} \\
\hline & & \multirow{2}{*}{$\begin{array}{c}\text { Bangladesh* } \\
\text { N/A }\end{array}$} & \multirow{2}{*}{$\begin{array}{c}\text { Bhutan } \\
9 \\
\end{array}$} & \multirow{2}{*}{$\begin{array}{c}\text { India } \\
194 \\
\end{array}$} & \multirow{2}{*}{$\begin{array}{c}\text { Nepal } \\
8 \\
\end{array}$} & \multirow{2}{*}{$\begin{array}{c}\text { Sri Lanka } \\
14 \\
\end{array}$} \\
\hline \multirow{3}{*}{5 Star } & No. of Hotels & & & & & \\
\hline & No. of Rooms & N/A & 212 & 18283 & 1539 & 3230 \\
\hline & No. of Beds & N/A & 424 & N/A & 2897 & 6420 \\
\hline \multirow{3}{*}{4 Star } & No. of Hotels & N/A & 8 & 114 & 2 & 18 \\
\hline & No. of Rooms & N/A & 196 & 8250 & 190 & 2070 \\
\hline & No. of Beds & N/A & 392 & N/A & 362 & 3863 \\
\hline \multirow{3}{*}{3 Star } & No. of Hotels & N/A & 45 & 634 & 15 & 14 \\
\hline & No. of Rooms & N/A & 1064 & 26463 & 596 & 1061 \\
\hline & No. of Beds & N/A & 2115 & N/A & 1107 & 2142 \\
\hline \multirow{3}{*}{2 Star } & No. of Hotels & $\mathrm{N} / \mathrm{A}$ & 42 & 122 & 26 & 33 \\
\hline & No. of Rooms & N/A & 1084 & 3160 & 1093 & 1717 \\
\hline & No. of Beds & N/A & 2145 & $\mathrm{~N} / \mathrm{A}$ & 2169 & 3381 \\
\hline \multirow{3}{*}{1 Star } & No. of Hotels & N/A & 19 & 86 & 24 & 33 \\
\hline & No. of Rooms & N/A & 249 & 2253 & 483 & 1325 \\
\hline & No. of Beds & N/A & 496 & N/A & 1252 & 2627 \\
\hline \multirow{3}{*}{ Non Star } & No. of Hotels & N/A & $\mathrm{NA}$ & 92 & 482 & 167 \\
\hline & No. of Rooms & N/A & NA & 4526 & 7934 & 6898 \\
\hline & No. of Beds & N/A & NA & N/A & 15084 & 15672 \\
\hline \multirow{3}{*}{ Total SASEC } & No. of Hotels & N/A & 123 & 1242 & 557 & 279 \\
\hline & No. of Rooms & N/A & 2805 & 76858 & 11835 & 16301 \\
\hline & No. of Beds & N/A & 5572 & N/A & 22871 & 34105 \\
\hline
\end{tabular}

Source: SLTDA (2013), GoI (2013), GoN (2013), TCB (2014)

*Data not available

The tourism in Asia Pacific Region has been the challenge for South Asian Region as both the regions are undertaking tourism as a major contributor to the socioeconomic 
development. Within South East Asia, Greater Mekong Sub-region (GMS) comprising China, Myanmar, Thailand, Laos, Cambodia and Vietnam have been undertaking the 11 flagship programs, including the tourism sector in its sub-regional development plan (GMS STDP 2011). The region have noticed tourism as one of the potential sector for employment and economic benefits for people across the region ensuring benefits of tourism to distribute equitably especially to the poor; minimizing the negative impacts of tourism on the country's culture and natural heritage on the environment and on the society as a whole. To enhance opportunity for economic development and with minimum threats to the communities, GMS countries have integrate ecotourism with mainstream tourism to support economic development of the country practicing CBET focusing more on management and capacity building of local communities in parallel. Moreover, the government of all GMS countries have been strongly supporting initiatives to expand the country's tourism sector and use tourism as a tool for poverty reduction, national socio-economic development and heritage conservation.

According to UNWTO (2014), in 2012, South-East Asia has remained the fastest growing sub region both in the region and in the world in 2013, with an increase of $11 \%$ in international tourist arrivals. Thailand has experienced the strong growth of $19 \%$, with 27 million tourists, 4 million more than in 2012. Among other destinations, Myanmar has come up with extensive progress in tourist arrivals in the last few years and recorded an extraordinary 52\% increase in 2013. Timor-Leste (up 42\%) and Cambodia (up 18\%) have also enjoyed high growth rates, together with Vietnam (up 11\%), the Philippines (up 10\%) and Indonesia (up 9\%).

Compared with South-East Asia, South Asia has shown little growth (up 6\%). Sri Lanka has been the highest growing country with $27 \%$ more tourists followed by Maldives $17 \%$ and Bhutan (up 10\%). The sub region's largest destination India (7 million arrivals) has been able to sustain only $6 \%$ growth. However, during the period, Nepal did experience a decline of $0.7 \%$ in arrivals compared to 2012 (UNWTO, 2014; Table 1). North-East Asia, the largest sub region in Asia and the Pacific with over half of all international arrivals in the region, has seen a $4 \%$ increase in 2013. Japan has recorded a growth of $24 \%$, reporting over 10 million arrivals for the first time ever. Taiwan (pr. of China) (up 10\%) and the Republic of Korea (up 9\%) have also experienced robust growth, together with Hong Kong (up 8\%) and Macao (up 5\%). China, however, the region's top destination, saw a decline of $4 \%$ in arrivals compared to 2012.

It is argued that though the "tourist arrival" figures are calculated on a monthly basis in Bangladesh, they are not accepted by many users within the country, because of allegation made on mode of data collection being not often dependable. Despite the Tourism Satellite Accounting System for aggregating the figures of tourist arrivals and earnings in practice, which have been introduced by the United Nations World Tourism Organisation (UNWTO), no authentic data is available on Bangladesh since 
2011. Cited in various articles published under tourism news events, critic say that in order to make tourism figures more reliable at the national and at the international levels, steps are undertaking by the government to modernize the methods of collecting such statistics.

Similarly, though domestic tourism among these five SASEC Sub-regional countries is equally prevalent, data is officially available only for India (Table 4). However, such tourism activities indicate that the region also generates large domestic tourist markets, whose main purpose is religious pilgrimage and visiting friends and relatives-based travel. It is noted however, that although large in volume, the domestic market has relatively short length of stay (2 to 3 days) and relatively low average daily expenditure, estimated at about one tenth of that of international tourists.

Table 4: Number of Domestic Tourists Visits to all States/UTs in India -2007-13

\begin{tabular}{|c|c|c|c|c|}
\hline Year & $\begin{array}{c}\text { NO. of Foreign } \\
\text { Tourists Visits } \\
\text { (In Millions) }\end{array}$ & $\begin{array}{c}\text { Percentage change } \\
\text { over the previous } \\
\text { Year }\end{array}$ & $\begin{array}{c}\text { NO. of Domestic } \\
\text { Tourists Visits } \\
\text { (In Millions) }\end{array}$ & $\begin{array}{c}\text { Percentage change } \\
\text { over the previous } \\
\text { Year }\end{array}$ \\
\hline $\mathbf{2 0 0 7}$ & 5.0 & 14.3 & 526.5 & 13.9 \\
\hline $\mathbf{2 0 0 8}$ & 5.2 & 4.0 & 563.0 & 6.9 \\
\hline $\mathbf{2 0 0 9}$ & 5.1 & -2.2 & 668.8 & 18.8 \\
\hline $\mathbf{2 0 1 0}$ & 5.7 & 11.2 & 747.7 & 11.8 \\
\hline $\mathbf{2 0 1 1}$ & 6.3 & 9.2 & 864.5 & 15.6 \\
\hline $\mathbf{2 0 1 2}$ & 6.5 & 4.3 & 1036.3 & 19.8 \\
\hline $\mathbf{2 0 1 3}$ & 6.9 & 5.9 & 1145.0 & 9.6 \\
\hline
\end{tabular}

Source: Ministry of Tourism, Government of India, 2013

Moreover, the regions' international and domestic tourism markets already support a broad range of transportation, accommodation, restaurant, travel and tour operation, tourism shopping, attraction and entertainment facilities and other services. World Travel and Tourism Council (2014) forecast that tourism activity in South Asia accounts for around 6\% of regional GDP, 37.2 million jobs, $\$ 116.1$ billion in total travel and tourism demand and $\$ 20.8$ billion in foreign exchange earnings. Likewise, WTTC (2014) data show that the domestic market accounts for most of the economic impact in terms of income and employment while the international market accounts for most of the value added to the economy.

Likewise, WTTC (2014) also forecasts that tourism and travel GDP in South Asia will remain increased by $10.3 \%$ per annum, employment by $4.3 \%$ per annum, overall tourism demand by $10.8 \%$ per annum and foreign exchange earnings by $11.2 \%$ per annum up to 2019. Individual country forecasts indicate that by 2020, the sub region's countries could potentially attract nearly 15 million international visitor 
arrivals as follows: (a) Bangladesh 900,000, (b) Bhutan 125,000, (c) India 8.9 million, (d) Nepal 2 million, and (e) Sri Lanka 3 million. It is stated that most tourists visit destinations within their own region. The large majority of international travel takes place within travellers' own regions, with about four out of five worldwide arrivals originating from the same region (UNWTO, 2014).

As suggested by Echtner and Ritchie, (1991); Cohn (1992); Pearce (1982); and Hunt (1975), the national images do, indeed, influence tourist behaviour and their perception towards the destination. Ultimately, it will have a decisive role in an individual's travel purchase related decision making process.

\section{Challenges for Destination Image Building in SASEC Countries}

\section{Nepal}

As suggested by various studies, there is no argument in the fact that tourism industry in Nepal is playing a significant role. For sustainable development of the national economy it comprises as one of the key development component. Furthermore, the geographical condition and the physical set up of the country have restrained Nepal to heave tourism as the largest potential industry.

According to the government statistics $(2013,2014 a)$ and WTTC (2014), tourism has included several forms of directly and indirectly productive activity in Nepal, where the possibilities of exporting manufactured goods are limited. Comparing to other developed and developing nations, Nepal also cannot ignore tourism because of its multifaceted effects such as on the balance of payments situation (US\$ 429.2 million earnings in 2013)., diversification of the economy (4.9\% of the total foreign exchange earnings in 2013), augmentation of revenues, and generation of employment opportunities directly (483,518 jobs) and indirectly (504,000 jobs).

An argument between government and the private entrepreneurs highlights that to achieve significant contribution from tourism and to reap maximum benefits, some changes in the existing tourism related policies of the government has to be urgently envisioned. To boost the national economy, prompt revision on the existing conventional approach of handling tourism industry has been seriously perceived by the industry. Likewise, debates among the industry stakeholders going on to make the existing tourism products more sustainable with changes and modifications, and to open up more areas with adding new products and services.

It has been observed that Nepal is now striving to project its image as a unique tourist destination in the international arena, in terms of quality of tourism products and services. Recent initiatives taken by the government with formulating strategic plan with 5 years action is directing towards diversification of tourism to new areas, addressing issues in the way of tourism promotion, rural community participation, private sector's involvement in tourism development, and exploitation of the linkages between tourism and other sectors of the economy. Moreover, it has been trying to 
focus more on to promote rural tourism and has encouraged local community to take part in the tourism related activities (MoCTCA 2014).

However, achieving successful integrated tourism development and better management depend on effective use of natural resources and minimisation of the negative impacts on society, culture and environment. Likewise, other factors such as policy development, physical planning and impact control also need careful assessments both at local and central level. The global tourism patterns have changed and have prompted adventure tourists and eco-tourists to visit new areas and spend liberally to new destinations. Change in expenditure patterns of adventure tourists is a positive sign for Nepal, especially to the rural community. It is commendable that, efforts have been taking by the government and the private sectors to open up new areas producing more new tourism products.

As there lie immense scope for tourism development, there is a notion that the full exploitation of the uniqueness the country has not been capitalize. It is also argued that to manage and to promote sustainable tourism, measures such as minimising the impacts on environment, culture and protecting sensitive area bio-diversity have to be followed restrictedly. Similarly, it is suggested to keep efforts on to introduce new tourism products to tourists all over the world with a thrust to promote national image as well.

\section{India}

Like in Nepal, tourism has also been one of the major sectors of the economy in India, contributing to a large proportion of the National Income and generating huge employment opportunities. It has become the fastest growing service industry in the country with great potentials for its further expansion and diversification. Literature suggests that the development of tourism started in India in a planned manner only from 1956 together with the Second Five Year Plan. The Sixth Plan marked the beginning of a new era when tourism began to be considered a major instrument for social integration and economic development.

However, it was only after the 80's that tourism activity gained momentum. A National Policy on tourism was announced in 1982. Later in 1988, the National Committee on Tourism formulated a comprehensive plan for achieving a sustainable growth in tourism. In 1992, a National Action Plan was prepared and in 1996 the National Strategy for Promotion of Tourism was drafted. In 1997, the New Tourism Policy recognised the roles of Central and State governments, public sector undertakings and the private sector in the development of tourism (WTTC 2014, 2014a).

According to the Government of India (2013), at present, tourism is the largest service industry, with a contribution of $6.2 \%$ to the national GDP and providing $7.7 \%$ of the total employment (WTTC, 2014). India has witnessed a 6.97 million foreign tourist and 1145 million domestic tourist arrivals in 2013. The tourism industry in 
India has generated about US\$18.44 billion in 2013 and that is expected to increase to US $\$ 275.5$ billion by 2018 at a $9.4 \%$ annual growth rate (GOI, 2013). The Ministry of Tourism is the nodal agency for the development and promotion of tourism and maintains the "Incredible India" campaign.

It is observed that recent initiatives taken by the Government to boost tourism include grant of export house status to the tourism sector and incentives for promoting private investment in the form of Income Tax exemptions, interest subsidy and reduced import duty. The hotel and tourism-related industry has been declared a high priority industry for foreign investment which entails automatic approval of direct investment up to 51 per cent of foreign equity and allowing 100 per cent non-resident Indian investment and simplifying rules regarding the grant of approval to travel agents, tour operators and tourist transport operators.

The major challenges in the development of tourism in India is the non-availability of adequate infrastructure including adequate air seat capacity, accessibility to tourist destinations, accommodation and trained manpower in sufficient number. Poor visitor experience, particularly, due to inadequate infrastructural facilities, poor hygienic conditions and incidents of touting and harassment of tourists in some places are factors that contribute to poor visitor experience.

\section{Bhutan}

According to the Tourism Council of Bhutan (2014), the country is practicing "high value, low impact" tourism for a longer period. It is argued that the country is fully aware of the negative impact of tourism, and the country has thus far carefully nurtured the industry. Nevertheless, the sector is now recognized as having considerable potential as a tool for development and as a contributor to national revenue and employment generation. For the first time ever, tourism industry was identified as a substantial socio-economic growth factor from the Ninth Five Year Plan (2002-2007) and has since been positioned as a priority sector. With international visitor arrival increasing every year, the sector is now seen as second only to Hydropower in terms of its potential to generate revenue and has emerged as the highest earner in foreign exchange.

Annual tourism statistics produced by BTC (2014) suggest that the tourism industry has been continuously growing in Bhutan at a steady rate with 116, 209 tourist arrivals in 2013 , marking a growth rate of $10.25 \%$ over the previous year. The international to regional visitor ratio was at 45:55, with growth rates more significant for the regional segment. Of the total international arrivals, a clear majority of $83.84 \%$ were for holidaying and leisure.

It is observed that Bhutan has been considered mainly as a cultural destination. Among total visitors in 2013, 72.0\% were for a cultural sightseeing tour followed by $8.0 \%$ to experience trekking and multiday hiking. The average length of stay of 
international visitors has been recorded only 6.85 days in 2013 due to the increase in top Asian markets that normally visit for shorter durations. Among potential tourists to Bhutan, many of them have combined their holiday with other countries like Nepal (29.10\%), India (23.90\%), and Thailand (20.0\%).

An analysis on visitor perceptions before coming to Bhutan shows that visitors were mainly motivated to experience the 'Unique culture', 'Pristine Nature', 'Gross National Happiness' and the 'Undiscovered specter' (TCB 2014). Favourable weather conditions, holiday timing, and Advice of Agents have been other main factors determining visitation time.

According to the TCB (2014), the results achieved from the departure survey done by the government in 2013 indicate that the challenges faced by Bhutan to build its national image and to sustain tourism growth exist improvements in 'roads', ' $r$ restroom facilities', 'garbage management', better hotels', etc. Similarly, the regional segment's main concern identified has been with 'online booking facilities' for hotels and Drukair airline service, lack of adequate information on hotels, difficulty to get hotels during peak period etc.

\section{Bangladesh}

According to the Government of Bangladesh it has recognized tourism as an important industry with the framing of a National Tourism Policy in 1992. In 1999, tourism was declared a Thrust Sector. However international arrivals have remained at low levels, and recently have declined from the high in 2007 of 397000 visitors. International arrivals to Bangladesh for 2010 totaled 303000, a 24\% drop from 2007. Since the arrivals have declined an average of $0.8 \%$ per annum for the period 2002 to 2006. The picture improved in 2007 with an estimated 397000 visitor arrivals, an increase of about $200 \%$ over 2006. Although visitor numbers and yield from Bangladesh's important Buddhist monuments and ecotourism attractions remain low, there is good potential for generating interest from target source markets with improved marketing, packaging and product development (http://www.parjatan.gov.bd/).

According to the tourism highlights indicated in UNWTO (2012) and ADB (2008) (Table 1), of the 303,000 foreign visitors in 2010 to Bangladesh, about 33\% reportedly came for holiday and leisure purposes. About $30 \%$ of all foreign arrivals were from India, followed by UK, USA and the PR China. Annual average growth in international arrivals have been in the order of 2\% during the period 1999 to 2006, and actually dropped 4\% from 2005. International arrivals to Bangladesh have been constrained by perceived access and visa issues, as well as a lack of preparedness of tourism attractions. However arrivals have recovered in 2007 with growth estimated at $200 \%$ over 2006.

While the beaches of Cox's Bazar receive the highest volume of domestic and Indian tourist arrivals in Bangladesh, with an estimated over one million visitors 
annually, there is growing interest in historic and cultural tours out of Dhaka and to the sites along the "Heritage Highway" through west Bangladesh. The ruins of the important Paharpur Buddhist monastery and the 15th century Shaat Gambus mosque at Bagerhat are both protected as UNESCO World Heritage Sites. Among total visitors in these UNESCO World Heritage Sites, less than $10 \%$ are estimated to be international visitors. Foreign visitors mainly Buddhist pilgrims visit Paharpur. In the 2005/2006 financial year, the Buddhist site of Mahastangarh received a total of 125,840 visitors. Bagerhat WHS received over 61,000 total visitors in 2006/2007, an increase of $15 \%$ over the previous year. Despite the lack of consistent data, the general picture from the sites is not clear though there seems growing demand (ADB, 2008).

Bangladesh is also having potential for ecotourism. Although access is difficult, the superb wildlife and natural attractions of Bangladesh's Sundarbans mangrove forests receive increasing numbers of domestic and international visitors. A journey by Rocket Steamer service from Dhaka (Sadarghat) to Khulna, the gateway to Sundarbans is considered a rewarding experience.

It is perceived that packaging the world heritage sites and other cultural and naturebased attractions that can be linked by the "Heritage Highway" concept could be the way to overcome some of the problems faced by Bangladesh tourism in terms of national image building. With improved access via Bagdogra and Dhaka, enhanced road conditions, visitor interpretation and systematic marketing, there is excellent potential to increase the currently low visitor numbers. In addition to Indian holidaymakers, future target markets are likely to be pre-booked cultural and special interest groups, some Free Individual Tourists (FITs) and expatriates living in South Asia. Wider international and intra-regional pilgrim segments can be eventually be attracted to Bangladesh's important Buddhist archeological sites.

\section{Sri Lanka}

According to Sri Lankan Tourism Development Authority (2013), Sri Lanka has attracted a record one million tourists to the country for the first time in history in 2012. Tourist arrivals surpassed its target of 950,000 to record 1,005,605 arrivals in 2012, an increase of 17.5 per cent over 2011 figure of 855,975 arrivals. Moreover, the total tourist arrivals in 2013 have recorded 1274,593 an increase of 26.7\% over 2012. The new products and refurbishment plans designed by Sri Lankan government have added to the tourism inventory towards achieving such growth. The national tourism strategy for 2011-2016 developed by Sri Lankan government has envisaged more number of arrivals as well as the value-addition to the Sri Lankan tourism industry, concentrating on the right type of tourists that Sri Lanka should have targeted.

The national tourism strategy plan $(2011$ - 2016) indicates that the Government of Sri Lanka has taken initiatives to make a concerted effort together with the industry towards sustaining the revival and boom in the tourism industry. Objectives set in 
the strategy are positioning Sri Lanka as one of the most sought after tourist destinations, including promoting tourism to reach 2.5 million tourist arrivals with annual foreign exchange earnings of US dollars 2.75 billion by 2016 while increasing direct and indirect employment to 500,000 (GoSL, 2010).

Meanwhile, the one-stop unit which has been established at the Sri Lanka Tourism Development Authority (SLTDA) has started facilitating for further investment to build more hotel rooms. The 'Home Stay' programme launched to provide more interactive facilities for tourists added 143 units alone in 2011 and has hoped to add more units in the years to come including hotels, boutique hotels, Home Stay units, guest houses and heritage homes.

It is argued that the 'Visit Sri Lanka 2011' programme helped all key attractions to put under 8 unique themes, namely, Heritage, Festive, Scenic, Essence, Thrills, Bliss, Pristine and Wild. MICE Tourism, which included Meetings, Incentive Travel, Conference and Exhibitions, also showed a healthy growth by contributing around 12 per cent in 2011. New locations for product development extended and identified.

To meet the challenges of a fast growing tourism industry and to retain the national tourism image, Sri Lanka has been creating more opportunities for training, and new developments initiation. Various efforts are underway including drafting a new Tourism Act, amalgamating the present four institutions with two institutions, viz Sri Lanka Tourism Authority and Sri Lanka Institute of Tourism and Hotel Management. Likewise, tourism sector related infrastructure and services expansion, addition of several international hotel chains and new airline companies, expansion of national carrier Sri Lankan Airlines routes and frequency to cater to the increasing demand from emerging market economies and traditional tourist markets in Europe. Moreover, Sri Lanka has been further initiating to promote lesser known attractions in all provinces in the country to attract potential travelers and investors through various promotional media.

\section{What really impedes for regional promotion}

Regardless of an impressive range of attractions, strong market potential, some relatively good tourism growth performances in recent years, and existing policy, planning and institutional arrangements, it is argued that the sub-regional countries have not been able to capitalize the full potential of tourism to contribute to a more environmentally sustainable and socially inclusive pattern of socio-economic development (ADB 2009).

The standards of tourist services and hospitality skills especially on the part of small and medium-sized tourism service providers are still limited. Visitors in these countries feel that the tourist information and site interpretation are generally inadequate and often absent. Likewise, the heritage assets of special interest to tourists such as major Buddhist monuments are in a poor state of conservation as indicated 
by their crumbling facades, illegal encroachments, and development of nonconforming structures at the sites or in their vicinity.

Comparing to the other neighboring regions, border facilities are inadequate and immigration procedures are cumbersome. Potential tourists in the source markets widely perceive the sub- region as a "difficult" destination to reach, and to safely and securely travel in. Infrastructure and services especially road, rail, and air connectivity, utilities such as water supply, electricity, sanitation, and solid waste management in destinations, and wayside amenities on access roads are generally in poor condition.

Similarly, the pattern of tourism development in the sub-region remains largely concentrated into a number of main urban destinations leaving many poorer communities (many of whom are located in or adjacent to highly attractive tourism resources) largely excluded from the benefits of tourism. Inadequate participation and investment by the private sector, meager destination marketing budgets and follow-the-leader based marketing approaches, and poor research-based statistical data are key institutional challenges confronting the tourism in the sub-region. Public and private sector tourism institutional capacities for partnering in tourism planning, development, regulation of standards, destination marketing, and tourism impact monitoring and evaluation are generally limited and weak. The infrastructure deficiencies combined with institutional constrains have created an unfavorable climate for private investment, which is vital to robust quality tourism development in the sub-region.

It is blamed that each country in the sub-region has been trying to carve out a niche in the market without harnessing the complementarities, and potential synergies that are available in the sub-region. Until recently, there had been little cooperation among these five countries in the development and promotion of tourism destinations and tour products even though many of them are critically dependent upon each other for market access. The latter has been further constrained by complicated and cumbersome cross-border travel procedures.

\section{Sub regional Cooperation a tool to Sustain National Images}

There is widespread enthusiasm for intraregional tourism, particularly in light of recent major fluctuations in inter-regional markets. Tourism development programs of all five South Asian Sub-regional countries should emphasize intra-regional tourism by building on flows from growing regional markets, and through cooperation to improve regional information flows. Increasing the number and status of international border crossings, developing networks to identify best practices, promoting crossborder packages, and linking infrastructure planning with tourism development will contribute to regional image building with expansion of intra-regional tourism. 
The widespread concern and impression of the tourist source markets as these five countries are "difficult" destination, needs to be overcome if tourism is to grow in the region. In addition to destination marketing programs promoting these common products to niche markets, other programs should aim at facilitating travel through such means as streamlining and simplifying visa and other border procedures, improving air connectivity, general security and transport safety, and improving public tourism services-such as customs, immigration, and tourist information services.

There is a wider common notion among SASEC countries that the individual tourism industries of these five countries must become more intra-regionally competitive. Concerned government of all countries should work to raise tourism industry standards in the sub region. This can be achieved through human resource development in the industry with other associated public services. Fostering privatepublic sector cooperation, reforming tourism regulations, and facilitating technology transfer through associations with foreign operators will also help. Encouraging investment including foreign direct investment (FDI) is essential in this regard. Similarly, facilitating dialogue between tourism and other sectors, improving banking and credit card services, and enabling "on line" booking through the Internet are also equally crucial.

The development and cooperation agenda for sub regional tourism development as envisaged in the previous projects funded by Asian Development Bank (ADB) such as SASEC Tourism Development Project (SASEC TDP) and South Asia Tourism Infrastructure Development Project (SATIDP) needs to be sustained and integrated by each country with a number of complementary interventions that will deepen the framework of support for marketing the sub-region as a single tourism destination as well as underpin the investments taking place under such project themes. Within the framework of the sub-regional multi-country circuit vision, the key complementary interventions that need to be integrated into a more comprehensive and coherent sub regional cooperation agenda must include: further streamlining cross border facilitation; destination marketing and promotion to expand tourism in the multi-country circuits; safeguarding heritage sites and enhancing the quality of tourism sites, facilities and services; encouraging private sector's participation; enhancing knowledge and experience sharing and human capacities; and augmenting linkages with broader regional cooperation initiatives in the above areas.

The South Asian Sub-regional Economic Cooperation (SASEC) program which began in 2001 with the establishment of a South Asian Growth Quadrangle comprised Bangladesh, Bhutan, India and Nepal. However, in 2005 Sri Lanka joined with the other four originating countries. The South Asia region and in particular the subregion comprising Nepal, Bangladesh, Bhutan, Sri Lanka and Indian is endowed with diverse cultural and natural resources. It includes many natural and cultural heritage sites inscribed in the World Heritage List, an ancient cultural heritage 
dating back over 5,000 years, and a rich diversity of ethnic groups with distinctive lifestyles. The region is the ancient heartland of Hinduism and Buddhism, and contains a landscape that includes the world's highest mountain Mt. Everest in the Himalayan range, and also some of the world's largest coastal mangrove forests and longest sea beaches, as well as containing internationally recognized biodiversity hotspots.

As indicated by global religious landscape (2012), there are over 488 million Buddhists worldwide representing approximately $7 \%$ of the global population of 2010 (Fig. 2). The enormous opportunity for Buddhist pilgrimage travel is now recognized within the sub region. The Footsteps of Lord Buddha sites associated with his life remain the core Buddhist Heartland attractions with potential for growth from pilgrimage and cultural sightseeing segments. Recent trends associated with the search for spiritual wellbeing appeal to broader, general interest visitors, including Westerners. "Living Buddhism" segments are now targeted by India and Sri Lanka, amongst others. With improved access, guiding and interpretation, the history, iconography and art associated with Buddhism in SASEC is a significant, untapped resource. In terms of new markets, there is potential to target higher-value segments from Asian countries with strong Buddhist connections, such as PR China, Japan, South Korea, Sri Lanka, Taiwan, and Thailand.

\section{Figure 2: Regional Distribution of Buddhist}

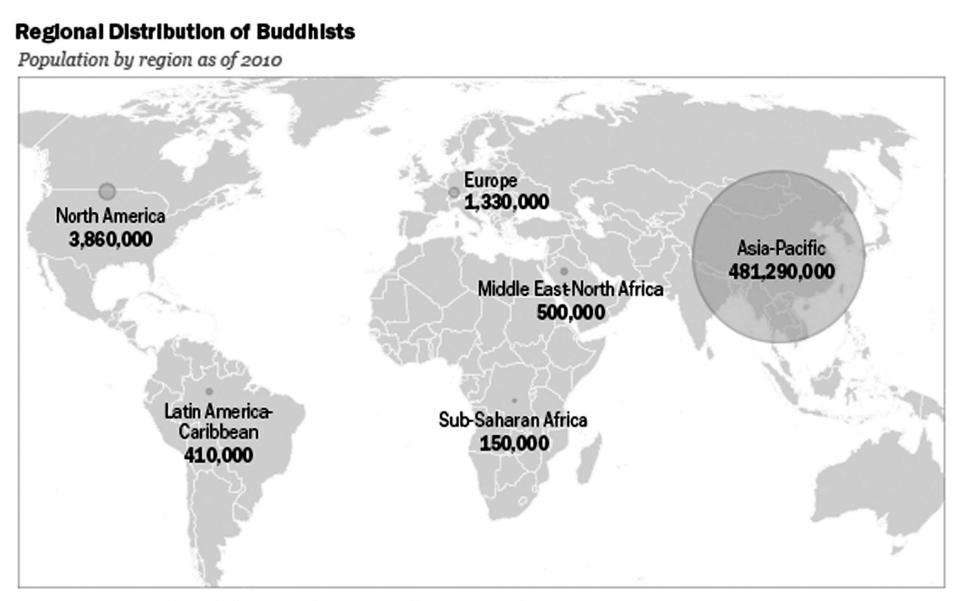

Percentage of world Buddhist population in each region as of 2010

SASEC countries are positioned as the "Buddhist Heartland" and feature some of the world's major Buddhist attractions, many of them recognized as World Heritage Sites. According to ADB (2008), Tourism Development Project (TDP) designed for SASEC countries identified the sub-themes of Footsteps of Lord Buddha, Living Buddhism in the Himalaya and Buddhist Art and Archaeology in South Asia. The Footsteps of Lord Buddha circuit in India and Nepal includes places directly associated 
with the Buddha's life. In order, these are Lumbini (birthplace), Sravasti, Sarnath (where Buddha gave his first sermon) to Bodh Gaya (where he attained enlightenment) to Rajgir, Nalanda, Vaishali, Kesaria to Kushinagar (where he died).

Many Hindus and Buddhists from all over the world also include visits to the Kathmandu Valley pilgrimage sites of Pashupatinath. Swayambhunath, Changunarayan, Bodhnath, and Namobuddha. Recent trends in the search for spiritual wellbeing (such as religious studies, traditional healing, Himalayan spas, yoga practices and meditation retreats) show up strongly in source markets. The cultural sightseeing markets are attracted by the sub region's historic monuments and religious centers, particularly the Living Buddhism found today in Nepal (Lumbini, Kathmandu Valley and mountain Buddhist centers along the Great Himalaya Trail), Bhutan, India (Arunachal Pradesh, Sikkim, Ladakh, Dharamshala etc.) and Sri Lanka (Ancient Cities, Kandy's Temple of the Tooth and Adam's Peak etc.).

The history, iconography and art associated with Hinduism and Buddhism can be found in important temples, monasteries and archaeological sites throughout the subregion. These include: Bangladesh (Paharpur, Mahasthangarh, Comila, Mainamati and Ramu); India (Madhya Pradesh (Samchi), Maharashtra (Ajanta and Ellora), Sikkim (Rumtek, Tashiding etc.), Ladakh; Orissa (Khandagiri, Udaygiri, Ratnagiri and Lalitgiri), Arunachal Pradesh (Tawang); Tripura (Pilak etc.); in Nepal (Kapilvastu, Tilaurakot, Arorakot, Gotihawa, Kudan, Niglihawa, Sagarhawa, Ramgram and Devdaha); and throughout Sri Lanka (ADB 2008).

Buddhist tourists range across a spectrum from pilgrims on a religious quest, to long-stay visitors pursuing religious and spiritual studies, and more general interest sightseers who may not have a religious motive. In addition to strong domestic and sub-regional pilgrims, arrivals and growth from the higher value international Buddhist tourism to South Asia are convincing. As indicated by Lumbini Development Trust (2013) in GON (2013), the number of visitors in Lumbini is 125,496 in 2013 and large numbers of foreigners are estimated to visit Lumbini (the birth place of Lord Buddha) in future and the famous stupas of Bouddhanath and Swayambhunath in Nepal. In Bhutan, nearly $30 \%$ of foreign visitors cite Buddhism as the major attraction. The Footsteps of the Buddha is attracting large number of pilgrims to the entire circuit but many more to individual destinations, mainly pilgrims from countries with high Buddhist populations. Bihar in India reports that $32 \%$ of international visitors come to this State in monasteries and dharamshalas. Japan accounts for almost $20 \%$ of all visitors to Bodh Gaya. Lumbini's estimated total of 125,498 foreign visitors in 2013 (ADB 2008, GON 2013).

In terms of potential market demand, strong growth is observed not only at Buddhist attractions in South Asia but also in other places in Asia, and mainly from Buddhist source markets. At major Buddhist monuments such as Angkor in Cambodia and Borobudur in Indonesia, massive recent growth is not only threatening the visitor 
experience but even said to be destroying the fabric of the building. In 2013, Siem Reap recorded 22,37,286 visitors attracted to Angkor, up from 20,63,336 visitors in 2012. The top three markets to Angkor are Korean, Japanese and Chinese who together accounted for nearly 26\% of all visitors in 2013(MOT 2013). Borobudur in Java received 3.2 million visitors in 2012, with major markets including Japan, Netherlands, Germany, British, France, Taiwan, Chinese and South Korea. Out of the total foreign arrivals to Sri Lanka, over 65\% visit Kandy, home of the relic of Lord Buddha housed in the Temple of the Tooth. Rumtek Monastery at Gangtok, the seat of the Kagyupa sect, receives an estimated 132,000 visitors annually, $10 \%$ of who are foreigners (ADB 2008).

In terms of the countries with the highest proportion of Buddhists, Thailand leads with $95 \%$ population. Japan (50\% proportion of Buddhists) will remain important with its historical connections and high disposable incomes, as is Vietnam (55\%), Macau (45\%) and Taiwan (43\%). Other countries with high proportions of Buddhists are Cambodia (90\%), Myanmar (88\%), Bhutan (75\%), Sri Lanka (70\%), Tibet (65\%) and Lao PDR (60\%). Focus can be given to promoting to the longer stay and higher yield Buddhist segments.

\section{Conclusion}

The sub regional patterns of tourism have remained unpretentious for many years, resulting in perceptions of "tired destinations". Despite strong government commitment to tourism now in all SASEC countries, world-class infrastructure and product development for the sector still remains inadequate. Impediments to travel such as difficulties with access, connectivity, visas, permits, and border procedures remain constraints, as do perceptions of security issues. However, still there is convincing potential for growth in both volume and yield from Hinduism, Buddhism and ecotourism market segments in all SASEC countries. Care needs to be taken to match products with market demand and to provide the high standards of guiding and interpretation that these markets require. Trekking in the Himalaya, ecotourism in the Ganga-Brahmaputra, and adventure in South Asia remain relevant subthemes. With their superb range of natural and cultural attractions, SASEC countries are uniquely well positioned to respond to the high value demand for cultural tourism products from long haul as well as short haul markets.

Given the existing situation, the main opportunities going forward to develop tourism and boost national images as a common agenda of South Asian Sub-regional countries are to:- (i) leverage potential strong market demand by tapping the synergy of complementary and contiguous tourism assets of the region through regional cooperation to create sustainable and socially inclusive sub regional thematic destinations and tour products, (ii) enable scale economies, (iii) expand existing and attract new markets, (iv) increase the size and distribution of the benefits of tourism, (v) harness the management and financial capability of the private sector 
in the development of tourism infrastructure and tourist facilities and services (especially community-based tourism development) and tour packages, as well as in the regulation of tourist site and facility and service standards, and in destination marketing, (vi) harness the knowledge and experience of the local communities for nature and culture-based ecotourism and (vii) create a regional destination marketing capability to provide an umbrella-marketing framework within which the countries can operate.

\section{References}

ADB, (2008). SASEC Tourism development Project, TA 6362 - REG, Final Report, July 2008

ADB, (2009). Report and Recommendation of the President of the Board of directors, October, 2009

Batson, J. (1991). Managing Services Marketing - Text and Readings, 2nd ed. London: Dryden.

Calantone, R. J., di Benetto, C.A., Hakam, A. and Bojanic, D.C., (1981). Multiple multinational tourism positioning using corresponding analysis, Journal of Travel Research, 28(2), 25-32.

Chon, K., (1989). Understanding Recreational Traveller's Motivation, Attitude and Satisfaction, The Tourist Review, 44 (1), 3-7.

Chon, K., (1990). The Role of Destination Image in Tourism: A Review and Discussion. The Tourist Review, 45(2), 2-9.

Chon, K., (1992a). The Role of Destination Image in Tourism: An Extention. The Tourist Review, 47(1), 2-7.

Chon, K., (1992b). Self - Image / Destination Image Congruity. Annals of Tourism Research, 19(2), 360-363.

Christopher, H.L., (1984). Services Marketing, New Jersey: Prentice Hall.

Cooper, C., Fletcher, J., Gilbert, D., and Wanhill S., (1993). Tourism Principles and Practice, London: Pitman.

Echtner, C.M., and Ritchie, J.R.B., (1991). The Meaning and Measurement of Destination Image, The Journal of Tourism Studies, 2(2), 2-11.

Echtner, C.M., and Ritchie, J.R.B., (1993). The Measurement of Destination Image: An Empirical Assessment. Journal of Travel Research, 31(2), 3-13.

GMS STDP (2011). A Baseline Report, GMS Sustainable Tourism development Project, Vietnam, December 2011.

GOI, (2013), Indian Tourism Statistics 2013, Ministry of Tourism, Government of India, 2013 
GON, (2013), Nepal Tourism Statistics 2013, Government of Nepal, Ministry of Culture, Tourism and Civil Aviation, 2013

Goodrich, J.N., (1978a). A New Approach to Image Analysis through Multidimensional Scaling, Journal of Travel Research, 17(4), 3-7.

Goodrich, J.N., (1978b). The relationship between preferences for and perceptions of vacations destinations: Application of a choice mode,. Journal of Travel Research, Fall, 8-13.

GoSL, (2010). Tourism Development Strategy, Ministry of Economic Development, Government of Sri Lanka

Hunt, J.D., (1975). Images As a Factor in Tourism Development, Journal of Travel Research, 13 Winter, 1-7.

Jenkins, C.L., and Henry, B.M., (1982). Government Involvement in Tourism in Developing Countries, Annals of Tourism Research, 9(4), 279.

Lavery, P., and Stevens, T., (1990). Attendance trends and future developments at Europe's leisure attractions, Travel and Tourism Analyst, 2, 52-75.

Mansfeld, Y., (1992). From Motivation To Actual Travel, Annals of Tourism Research, $193), 399-419$.

Mathieson, A., and Wall, G., (1982). Tourism: Economic, Physical and Social Impacts, London: Longman.

Mayo, E.J., (1973). Regional Images and Regional Travel Behaviour, Proceedings of the Travel Research Association Fourth Annual Conference, 211-218.

MoCTCA, (2014). Draft National Tourism Strategy and Action Plan ( 2014 - 2023), Ministry of Culture, Tourism and Civil Aviation, Government of Nepal.

MoCTCA, (2014a). Tourism Employment Survey 2014, Ministry of Culture, Tourism and Civil Aviation, Government of Nepal

MOT, (2013). Tourism Statistics Report 2013, Ministry of Tourism, Cambodia

Pearce, P.L., (1982). Perceived Changes in Holiday Destinations, Annals of Tourism Research, 9(2), 145-164.

Pearce, P.L., (1985). A Systematic Comparison of Travel - Related Roles, Human Relations, 38, 1001-1011.

Pizam, A., (1978). Dimensions of Tourist Satisfaction with a Destination Area, Annals of Tourism Research, 5(3), 314-321.

SLTDA (2013), Annual Statistical Report of Sri Lanka Tourism 2013, Sri Lanka Tourism Development Authority, Colombo, Sri Lanka

TCB, (2014). Bhutan Tourism Monitor, Annual Report 2013, Kingdom of Bhutan, Tourism Council of Bhutan 2014 
UNWTO, (2005). Making Tourism More Sustainable - A Guide for Policy Makers, UNEP and UNWTO, 2005, p.11-12

UNWTO, (2008). World Tourism Barometer, Volume 6, No. 1, January 2008

UNWTO, (2012). Tourism Highlights, 2012,

UNWTO, (2014). Tourism Highlights, 2014,

UNWTO, (2014a). World Tourism Barometer, Volume 12, No. 1, January 2014

Van Raaij, W.F., and Francken, D.A., (1984). Vacation Decisions, Activities and Satisfaction, Annals of Tourism Research, 11(3), 101-112.

World Bank, (2013). Tourism Cluster Analysis for Nepal Competitive Industry Diagnostic, The World Bank, 2013

WTTC, (2014), Travel and Tourism Economic Impact South Asia, World Travel and Tourism Council, London, UK 2014

http://www.in2ition.biz/2013/05/01/sri-lanka-tourism-development-strategy-for2011-2016-part-1/

http://www.parjatan.gov.bd/

http://www.slideshare.net/MaharaniDianPermanas/world-heritage-borobudur http://www.trcollege.net/articles/74-development-and-impact-of-tourism-industryin-india

http://www.world-tourism.org/facts/tmt.html

http://www.wttc.org/eng/Tourism_Research/Tourism_Economic_Research/Monthl y_Update_of_Tourism_Indicators/index.php 